\title{
CONCEPCIONES DE LA PRUEBA JUDICIAL
}

\section{Rodrigo Vargas Ávila*}

Fecha de recepción: 15 de junio de 2011

Fecha de aprobación: 16 de noviembre de 2011

Artículo de Reflexión

\begin{abstract}
Resumen
Este trabajo a la vez que busca divulgar tendencias contemporáneas del pensamiento filosófico en torno a una nueva teoría general de la prueba bajo enfoques epistemológicos, de la misma manera pretende relievar la importancia de los hechos y su conocimiento en el proceso judicial en términos de verdad, entendida dentro de los límites del conocimiento racional empírico.
\end{abstract}

Una de las ramas de la filosofía que permite este cambio es la espistemología que a través de sus pensadores propone el entendimiento de los esquemas internos del pensamiento tratando de ordenar y sistematizar las etapas que llevan a una determinada conclusión. Su utilidad se traduce en la comprensión de los razonamientos probatorios que realiza el juez en el proceso, para ayudarle en su ordenación y, por ende, permitirle motivar mejor.

Así pues, el juicio de hecho en el proceso exige diferenciar una faceta epistemológica y otra normativa, las cuales se relacionan en un momento particular del proceso: al establecer los hechos relevantes del caso -hechos a probar-y al valorar si ellos se encuentran corroborados - hechos probados-.

\section{Palabras clave}

Hechos. Enunciado Fáctico. Prueba. Epistemologóía. Racionalidad. Proceso. Verdad.

\section{CONCEPTIONS OF THE JUDICIAL PROOF}

\begin{abstract}
This work at the same time seeks to disseminate contemporary philosophical trends around a new general theory of the test under epistemological approaches in the same way intended to highlight the importance of the facts and knowledge in the judicial process in terms of truth, understood within the limits of rational knowledge empirically.
\end{abstract}

* Abogado Especializado en Instituciones Jurídico Familiares de la Facultad de Derecho, Ciencias Políticas y Sociales de la Universidad Nacional de Colombia; Docente de la misma Universidad; Profesor de Derecho Procesal, Probatorio y de Teoría general de la Prueba de la Facultad de Derecho de la Universidad Militar Nueva Granada; investigador en las áreas del Derecho Procesal, Probatorio y Derecho Privado; conferencista; consultor en derecho privado y público; miembro del Instituto Colombiano de Derecho Procesal; exmagistrado auxiliar del Consejo de Estado. Actualmente candidato a Maestría de la Facultad de Derecho de la Universidad de los Andes. Correo electrónico: rodrigo.vargas@unimilitar.edu.co. 
One branch of philosophy that allows this change is the epistemology that through its thinkers proposes an understanding of internal patterns of thought trying to organize and systematize the steps leading to a particular conclusion. Its use results in the understanding of the arguments made by the judge evidence in the process, to help in their management and thus enable better purpose.

Thus, the trial done in the differentiation process requires an epistemological and a normative aspect, which are related in a particular moment of the process: to establish the relevant facts of the case-made test-and assess whether they are corroborated - proven facts.

\section{Keywords}

Acts. Factual statement. Test. Epistemology. Rationality. Process. Truth.

\section{CONCEPÇÕES DA PROVA JUDICIAL}

\section{Resumo}

Este trabalho ao mesmo tempo, busca divulgar as tendências filosóficas contemporâneas em torno de uma nova teoria geral do teste sob abordagens epistemológicas da mesma forma que pretende destacar a importância dos fatos e conhecimento no processo judicial em termos de verdade, compreendida dentro dos limites do conhecimento racional empiricamente.

Um ramo da filosofia que permite que esta mudança é a epistemologia que através de seus pensadores propõe uma compreensão dos padrões internos de pensamento tentando organizar e sistematizar os passos que levam a uma conclusão particular. Seu uso resulta na compreensão dos argumentos apresentados pela evidência juiz no processo, para ajudar na sua gestão e, assim, permitir uma melhor finalidade.

Assim, o julgamento feito no processo de diferenciação requer um epistemológico e um aspecto normativo, que são relacionados em um determinado momento do processo: para apurar os factos relevantes do caso- fatos para provar- avaliar se eles são corroborados - Fatos provados-

\section{Palavras-chave}

Fatos, Declaração factual. Teste. Epistemologia. Racionalidade. Processo. Verdade

\section{INTRODUCCIÓN}

En este artículo se busca describir las teorías que bajo un enfoque epistemológico, tratan de demostrar que la valoración de la prueba en el contexto del proceso judicial, debe estar orientada bajo criterios de racionalidad aunque no se trate de una racionalidad deductiva o demostrativa, y que tales criterios deben ser los que con posterioridad permitan justificar o motivar la declaración de los hechos de la sentencia.

En tal forma, el problema que subyace a esta discusión radica en la relación que existe entre las concepciones epistemológicas acerca del conocimiento de la realidad y el análisis de los 
fines del proceso y de la prueba judicial desde la perspectiva de la verdad, bien sea como certeza o como probabilidad. A este respecto, existen dos formas contrapuestas de plantear el problema de la verdad como finalidad del proceso y de la prueba judicial.

El aspecto común a ambas teorías parte de entender la relación entre "prueba y verdad", cuya discusión gira alrededor de los "hechos" entidades epistémico-semióticas con las cuales aprehendemos y constituímos algún aspecto de la realidad o del mundo físico en la esfera del conocimiento racional, que para efectos del proceso judicial no han sido presenciados por el juez, en tal forma que deben ser reconstruidos por el juzgador de los "hechos" tomando como base los medios de prueba disponibles para su determinación en el ámbito concreto del proceso. Es usual que las pruebas sirvan para "fundar $y$ controlar la verdad de las afirmaciones que tienen a esos hechos por objeto"(Taruffo, 2002, p. 23).

Este rasgo es el que servirá para que una y otra concepción acerca de la prueba, conciban positiva o negativamente como alcanzable o no,

1 "Cuando se habla de "construcción", "definición" o "identificación" del hecho, o de individualización del nivel de realidad o del grado de precisión en el que aquél es determinado, o también del modo en que las normas individualizan los hechos juridicamente relevantes, parece evidente que no se hace referencia al hecho en cuanto ocurrencia de la realidad empírica. Los hechos del mundo real existen (cuando existen) según modalidades empíricas absolutamente independientes de la esfera de las determinaciones conceptuales, valorativas o normativas: no son los eventos del mundo real los que se "construyen", "definen" o "identifican", porque éstos, por decirlo así, "suceden" de forma absolutamente independiente de las categorías, de los conceptos y de las valoraciones que a ellos se refieren. Lo que se construye o se define en función de conceptos, valores o normas son enunciados relativos a hechos del mundo real o, en el caso de hechos particularmente complejos, versiones de segmentos de experiencia o sectores de la realidad, que tienen relevancia en el juicio.

En consecuencia, en el proceso "el hecho" es en realidad lo que se dice acerca de un hecho, es la enunciación de un hecho, no el objeto empírico que es enunciado". TARUFFO, Michele. La prueba de los hechos. Madrid: Trotta. 2002. p. 21. la verdad, tanto en el proceso como de la prueba de los hechos en $\mathrm{el}^{2}$.

En tal sentido, la premisa básica a partir de la cual se pueden estudiar las concepciones de la prueba consiste en el tipo de epistemología que se adopte. En efecto, "en la medida en que la prueba judicial es un juicio sobre la ocurrencia de hechos (generalmente hechos del pasado que no han sido presenciados por el juzgador), la concepción de la prueba que se mantenga se vincula al modo en que se entiendan la naturaleza, posibilidades y límites del conocimiento empírico"(Gascón, 2003, p. 1).

Uno de los objetivos de la epistemología consiste en generar condiciones para que el conocimiento de la realidad -objetiva o constructiva- sea verdadero. Con todo, no existe una única y verdadera teoría del conocimiento que suministre un concepto de verdad infalible en ninguno de los ámbitos del conocimiento $\mathrm{y}$, por ende, tampoco la hay para la teoría del proceso y de la prueba judicial.

Un problema central de la epistemología, es entonces, el concepto de realidad y su proyección en el conocimiento racional de los diferentes fenómenos. Esta pregunta sobre el concepto de lo real es una indagación sobre la posibilidad o no de un conocimiento objetivo del mundo.

2 Expresa la Corte Constitucional "[E]l legislador haciendo uso del principio inquisitivo, faculta al juez de segunda instancia para decretar de oficio las pruebas que considere necesarias para encontrar o aproximarse a la realidad histórica de la controversia planteada. Debe acotarse que ello no viola la Constitución, pues tal atribución se encuentra condicionada a que el decreto y práctica de pruebas sean indispensables para resolver la apelación o la consulta planteada.

Por lo demás, a juicio de la Corte, si la justicia es un elemento fundante del nuevo orden constitucional, valor y principio constitucional que debe ser realizado como fin propio de la organización estatal, constituye un deber y no una mera facultad la posibilidad de que se decreten pruebas de oficio. Naturalmente ello estará determinado por la necesidad de que se alleguen al proceso los elementos de juicio requeridos para que se adopte una decisión ajustada al derecho y a la equidad". Sentencia C-1270 de 2000. 
Así, una epistemología objetivista, comprende que la objetividad del conocimiento radica en su correspondencia o adecuación a un mundo independiente, $\mathrm{y}$ al concebir el conocimiento como un proceso guiado por reglas más o menos seguras confía en la obtención de certeza absoluta, como es el caso de los modelos de prueba legal o de prueba tasada que fijan en normas reglas de valoración que le señalan al juez en qué condiciones debe dar por probado un hecho. Pero también, se encuentra en la comprensión habitual que se ha dado al principio de la libre valoración de la prueba de manera independiente a los medios de prueba y como una íntima convicción, bajo la característica de la discrecionalidad del juzgador, siendo la prueba una actividad subjetiva $y$, por ende, incontrolable.

De otra parte, la epistemología subjetivista, a su vez, entiende que la objetividad del conocimiento deriva de nuestros esquemas de pensamiento y juicios de valor, es decir, el conocimiento del mundo está contaminado, es irreductiblemente subjetivo, y por lo tanto, dejan en un segundo plano el conocimiento de los hechos para otorgar prioridad a otras finalidades prácticas del proceso o niegan la posibilidad racional del juicio de hecho en la valoración de la prueba. En consecuencia, para esta última concepción de la prueba, verdadero es lo que resulta probado en el proceso.

Bajo esta concepción se encuentran aquellas posturas que relegan la verdad como fin de la prueba y del proceso a un papel secundario; sostienen que la prueba es una actividad primordialmente subjetiva, y por tanto, no controlable $e$ irracional, mientras que el fin del proceso es resolver un conflicto (Montero, 2007, p. 44).

La relación que existe entre las concepciones epistemológicas acerca del conocimiento de la realidad y el análisis de los fines del proceso y de la prueba judicial desde el tópico de la verdad, bien sea en términos de certeza o de probabilidad es problemática. A este respecto, existen dos formas contrapuestas de plantear el problema de la verdad como finalidad del proceso y de la prueba judicial. Estas concepciones cada una de las cuales se caracteriza por establecer un nexo entre los conceptos de verdad y prueba, son dos: concepción de la prueba cognoscitivista y concepción persuasiva de la prueba. Cabe señalar, que para establecer una distinción entre las dos concepciones de la prueba expuestas, su análisis se hará a través de la relación entre los conceptos de verdad y prueba.

\section{CONCEPCIÓN COGNOSCITIVISTA DE LA PRUEBA}

Bajo esta concepción se parte de una relación directa entre prueba y teoría del conocimiento. Concibe que el juicio de la prueba en el proceso judicial incluye un problema de racionalidad fáctico-procesal que debe estar apoyado en un enfoque epistemológico de la realidad ${ }^{3}$. Esta es la llamada concepción racionalista o cognoscitivista de la prueba. En ella se opta por una finalidad

Expresa la Corte Suprema de Justicia al acoger esta orientación, como "[e]n las controversias judiciales, por regla general, cada una de las partes acude al juez con su propia versión de los hechos, esto es, que presenta enunciados descriptivos o proposiciones fácticas a partir de las cuales pretende generar un grado de convencimiento tal, que sea suficiente para que se emita un pronunciamiento favorable al ruego que se eleva ante la jurisdicción. Dicho de otro modo, en el punto de partida de toda controversia procesal, cada uno de los extremos del litigio intenta convencer al juez de que las descripciones que presenta coinciden con la realidad y, a partir de aquéllas, justamente, propicia el litigio.

De esa manera, cuando hay una genuina contención, el sistema exige que cada uno de los contendientes correlativamente contribuya a que el juez supere el estado de ignorancia en el que se halla respecto de los hechos debatidos, tarea que por lo general concierne al demandante respecto de sus pretensiones, y al demandado respecto de las excepciones.

Desde luego, al juez no le basta la mera enunciación de las partes para sentenciar la controversia, porque ello sería tanto como permitirles sacar beneficio del discurso persuasivo que presentan; por ende, la ley impone a cada extremo del litigio la tarea de traer al juicio de manera oportuna y conforme a las ritualidades del caso, los elementos probatorios destinados a verificar que los hechos alegados efectivamente sucedieron, o que son del modo como se presentaron, todo con miras a que se surta la consecuencia jurídica de las normas sustanciales que se invocan". Sentencia del 25 de mayo de 2010. Expediente No. 23001-31-10-002-1998- 00467-01. 
epistemológica o cognoscitivista del proceso y de la prueba judicial, esto es, se vincula a la prueba en su fin con la verdad o de relativo grado de correspondencia empírica con un aspecto del mundo ontológico (Ferrajoli, 1977, p. 67) ${ }^{4}$. Es así, como bajo esta concepción:

[L]os procedimientos de fijación de los hechos se dirigen a la formulación de enunciados fácticos que serán verdaderos si los hechos que describen han sucedido y falsos en caso contrario. (...). La fijación de los hechos no puede ser, por ejemplo, consecuencia del puro decisionismo o constructivismo, sino el resultado de un juicio descriptivo de hechos a los que se atribuye 'existencia independiente'. Por ello, el concepto de verdad requerido por el modelo es el semántico de la correspondencia y el principal criterio de verdad el de la contrastación empírica (Gascón, 2004, p. 53 y Taruffo, 2010, p. 531).

Por tal razón, cuando se expresa que un enunciado fáctico es verdadero quiere decir que los hechos a los cuales el se refiere han tenido o tienen ocurrencia en un mundo independiente, o que se corresponde con la realidad ${ }^{5}$. Desde esta

4 "Esta es la única concepción de la prueba que se acomoda a una actitud epistemológica no dogmática, pues, a diferencia de la concepción persuasiva, que no permite pensar que la declaración de hechos de la sentencia sea falsa, ésta sí permite pensarlo: "permite sostener la hipótesis de que un imputado podría ser inocente (o culpable) aunque tal hipótesis haya sido rechazada en todas las instancias de un proceso y esté en contraste con todas las pruebas disponibles". FERRAJOLI, Luigi. Derecho y razón. Madrid: Trotta. 1997. p. 67.

5 "Ahora bien, las más de las veces, la carga demostrativa que se hace descansar a hombros de los contendientes, sirve para abastecer al proceso de la mayor cantidad posible de trazas históricas, útiles al propósito de reconstruir los hechos debatidos, es decir, para hallar la verdad como correspondencia entre los enunciados que se hacen acerca de la realidad y la realidad misma. Como la actividad de las partes en el proceso es de suyo competitiva, el juez usualmente tendrá entonces dos visiones inconciliables que se neutralizan, pero que a la vez contribuyen al esclarecimiento de los hechos. Dicho de otro modo, el afán por defender una determinada posición exige y fomenta la participación pespectiva el cognoscitivismo separa el enunciado fáctico verdadero del enunciado fáctico probado; este último, se hace consistir en que su verdad ha sido comprobada o confirmada por las pruebas disponibles en el proceso. Por ello, un problema ulterior consistiría en que la declaración de los hechos probados consignada en la sentencia puede ser falsa.

Ahora, el concepto de verdad o enunciado verdadero en relación con el de prueba o enunciado probado indica un ideal, que en esta distinción

de los litigantes en la etapa probatoria y cada una de esas intervenciones contribuye, en buena medida, a la actividad del juez, que entre la cooperación de los concernidos y los límites de la competencia, debe asumir una participación decisiva en el hallazgo de la verdad, desideratum del proceso tan esquivo, como necesario.

Entonces, el juez aborda una realidad extinta para superar el desconocimiento de los hechos con el que despunta todo litigio, y sobre el saber que le brindan las pruebas -analizadas todas bajo el tamiz de la sana crítica-, verifica los enunciados normativos que ilustran el caso y en la sentencia, que es la pieza principal de la actuación, adopta las decisiones que el ordenamiento jurídico consagra, todo con miras a lograr la efectividad del derecho sustancial, cual ordenan perentoriamente diversos cánones constitucionales, y con el propósito último de disipar la incertidumbre que se cierne sobre los derechos en litigio.

$\mathrm{Y}$ en ese escenario, cuando se clausura la primera instancia, es posible que las partes, apoyadas en razonamientos plausibles $\mathrm{o}$, incluso, validas de una infundada obstinación, tomen las pruebas que militan en el expediente e intenten, a su manera y bajo su siempre interesada perspectiva, una nueva lectura, diferente a la que hace el juez en su sentencia, para construir razonamientos disímiles a partir de los mismos elementos de convicción.

Sin duda, el escenario democrático del proceso debe permitir en el curso de las instancias ese tipo de ejercicios, pues la confrontación dialéctica enriquece el debate judicial y provoca reflexiones de gran valía a la hora de dar solución a la controversia, lo cual hace del diálogo un instrumento fundamental en el afán de hallar la verdad. Para ello, precisamente, se llama a las partes con el fin de que ilustren con fundamento la alzada -cuando ella procede-, recurso en cuya decisión han de analizarse los argumentos oportunamente expuestos, con miras a someter la sentencia al veredicto de la razón, en un escenario crítico en el que los contendientes procesales han de expresarse en identidad de circunstancias". Sentencia del 25 de mayo de 2010. Expediente No. 23001-3110-002-1998-00467-01. 
destaca las limitaciones de que el procedimiento probatorio adolece en la averiguación de la realidad de los hechos que han sucedido con anterioridad al inicio de un proceso, pues si bien, es relevante juridicamente la declaración de hechos probados ella no es infalible. De allí, el carácter autorizado pero falible de la declaración de hechos en la sentencia (Gascón, 2005 y Taruffo, 2006).

La concepción epistemológica de la prueba agrega el argumento de la justicia de la decisión judicial. Esta es la concepción que se conoce como racionalismo crítico, según el cual "si queremos un proceso justo, hemos de asegurarnos de que esté orientado al descubrimiento de la verdad, y para ello debe sujetarse a ciertos requisitos de racionalidad epistemológica"(González, 2003, pp. 17-26). De tal manera, puede decirse que la justicia de una decisión tiene como condición necesaria la verdad de los enunciados fácticos que le dan fundamento (Taruffo, 2006, p. 413)6.

Además, en la concepción racionalista-crítica, lo relevante de postular una relación entre el fin del proceso judicial y una concepción epistemológica de la realidad, es la posibilidad de exigencia de justificación razonable de los enunciados fácticos con los cuales se declaran probados los hechos en la sentencia. Por eso, el proceso como contexto y la sentencia como resultado no son un simple espacio de narratividad con técnicas de relato persuasivo $^{7}$, pero tampoco una consecuencia

6 "La justicia de la decisión no presupone solamente su legalidad, es decir, que se derive de una correcta interpretación y aplicación de las normas, sino también su veracidad, es decir, la determinación de la verdad de los hechos relevantes: la razón fundamental de esto es que ninguna decisión puede considerarse justa si se basa en una determinación falsa o errada de los hechos de la causa". TARUFFO, Michele. Páginas sobre justicia civil. Madrid: Marcial Pons. 2010. p. 413.

7 "Esto lleva a excluir que sea realmente aplicable en el contexto procesal, una concepción radicalmente $<<$ narrativista $>>$ de la verdad, según la cual la verdad de un enunciado fáctico podría depender sólo de su coherencia con otros enunciados, en el ámbito de una naeeción que se asume como la única dimensión en la que tendría sentido hablar de los hechos". (...). "En realidad, el proceso sigue siendo un lugar en el lógica del trabajo probatorio tarifado o tasado por el legislador, al estilo de un cognoscitivismo acrítico8, en el que la motivación de los hechos por el juez contiene una sustracción de materia, puesto que él como agente del legislador no puede ser sucedáneo de éste a la hora de la valoración probatoria (Gascón, 2004, p. 44).

\section{CONCEPCIÓN PERSUASIVA DE LA PRUEBA}

El fundamento básico de esta concepción radica en que concibe la prueba jurídica como un instrumento de persuasión, en lugar de constituir una actividad epistemológica, que no tiene relación con el conocimiento racional de hechos. Conforme a esta concepción, la averiguación de la verdad "real", "objetiva" o "correspondiente" de los hechos no es la finalidad que debe tener el proceso, puesto que de él se predican objetivos y finalidades más prácticas y socialmente útiles ${ }^{9}$. De

que se tiende a establecer cuál es la narración $<<$ más verdadera $>>$ en cunato confirmada por las pruebas disponibles, dado que es la confirmación probatoria de la verdad de los hechos donde reside la condición fundamental de justicia de la decisión". TARUFFO, Ob. Cit., p. 532.

8 Concepción bajo la cual se entiende que "el fin instrumental del proceso es averiguar la verdad de las aserciones (en el sentido de correspondencia con los hechos que describen), pero, al concebir la prueba judicial como un proceso guiado por reglas mas o menos seguras, confia en la posibilidad de obtener resultados incuestionables". Sin embargo, su postulación es débil, porque elude distinguir entre verdadero y probado, que tiene por fundamento el reconocer las limitaciones del conocimiento relativo alcanzado en el proceso judicial. GASCON ABELLAN, Marina. Concepciones de la prueba. Madrid: Discusiones, No. 04. 2003. p. 47.

9 Un buen ejemplo de contraste frente a esta postura es el señalado por la Corte Constitucional al analizar la constitucionalidad del artículo 220 del C. de P. P. (Ley 600 de 2000) al señalar, citando a la Corte Interamericana que "[e]n ciertas circunstancias puede resultar difícil la investigación de hechos que atenten contra derechos de la persona.

La de investigar es, como la de prevenir, una obligación de medio o de comportamiento que no es incumplida por el solo hecho de que la investigación no produzca un resultado satisfactorio. Sin embargo, debe emprenderse con seriedad y no como una simple 
tal manera, que la actividad probatoria que en él se suscita, debe perseguir la solución institucional del conflicto o la resolucíon de un conflicto ${ }^{10}$.

formalidad condenada de antemano a ser infructuosa. Debe tener un sentido y ser asumida por el Estado como un deber jurídico propio y no como una simple gestión de intereses particulares que dependa de la iniciativa procesal de la víctima o de sus familiares o de la aportación privada de elementos probatorios, sin que la autoridad pública busque efectivamente la verdad. Esta apreciación es válida cualquiera sea el agente al cual pueda eventualmente atribuirse la violación, aun los particulares, pues, si sus hechos no son investigados con seriedad, resultarían, en cierto modo, auxiliados por el poder público, lo que comprometería la responsabilidad internacional del Estado (subrayas no originales)."

El deber investigativo del Estado de los hechos punibles y los derechos constitucionales de las víctimas, que se encuentra íntimamente ligado al deber de las autoridades de asegurar la vigencia de un orden justo (CP Preámbulo y art. $2^{\circ}$ ), no son tampoco absolutos, y por ello no pueden ser invocados para arrasar con la seguridad jurídica y los derechos del procesado, que son también principios de rango constitucional (CP art. 29)."(Sentencia C-004 de 2003).

En ocasión posterior sostuvo: "Al respecto, es preciso señalar que la Corte Constitucional, en diversas sentencias ha considerado que la garantía de los derechos a la verdad, la justicia y la reparación constituyen fines de todo proceso penal. Sin embargo, también es cierto que el origen de aquéllos se encuentra en el derecho internacional de los derechos humanos y que su evolución se ha visto enmarcada en el examen de situaciones concretas que configuran graves violaciones de aquéllos. De allí que, si bien toda víctima de un delito es titular de los derechos a la verdad, la justicia y la reparación, también lo es que el contenido y alcance de estos derechos no resulta ser idéntico cuando se está ante conductas que configuran graves violaciones de derechos humanos. En efecto, piénsese, por ejemplo, en la dimensión objetiva que presenta el derecho a la verdad, en tanto que derecho que le asiste a una sociedad a conocer su pasado; en las medidas de reparación simbólica de que son titulares las minorías étnicas que han sido víctimas de crímenes de lesa humanidad; o incluso, en las garantías de no repetición en casos de delitos sistemáticos cometidos por agentes estatales. En todos estos casos, los derechos a la verdad, la justicia y la reparación adquieren una dimensión distinta de aquella que presentan cuando quiera que se cometa un delito común". (Sentencia C-828/10).

10 Se puede citar como ejemplo el siguiente, dentro del Código de Procedimiento Penal (Ley 906 de 2004), en relación con el principio de razón suficiente, bajo el cual se relega el concepto de verdad en beneficio
En efecto, dice Taruffo, que en esta concepción:

[l]a prueba no serviría, pues, para establecer la verdad o falsedad de enunciado alguno $y$, por tanto, tampoco para proporcionar conocimiento acerca de nada, sino que serviría sólo para persuadir al juez, para convencerlo de lo fundado o infundado de un enunciado fáctico. La prueba, según esta concepción, no ofrece información sino elementos de persuasión. Es decir, en el juicio no se "conocen" los hechos: todo se agota en los discursos y narraciones que se hacen en el proceso, y de esa manera se puede definir como verdadero el enunciado del cual el juez está persuadido, pero sólo en función del hecho de que realmente lo esté y afirme estarlo. Cualquier cosa que piense el juez, estando persuadido de ella, está probada y, por lo tanto, se puede considerar verdadera a los efectos del

de la resolución del conflicto: "En efecto, la figura del allanamiento a la imputación o a los cargos por parte del procesado significa que la razón suficiente para afirmar, por parte de la judicatura, que unos hechos ocurrieron de una determinada manera no encuentra su razón suficiente y eficiente en pruebas practicadas dentro del proceso, sino que la razón suficiente y eficiente es el allanamiento o la aceptación de cargos. En igual sentido, podemos afirmar que la institución de las estipulaciones probatorias, o acuerdos celebrados entre la Fiscalía y la defensa para aceptar como probados alguno o algunos de los hechos o sus circunstancias, implica que el hecho que se pretende establecer con el convenio o acuerdo que defensa y fiscalía hacen en un momento sobre la prueba y el hecho que se va a dar por probado, y si este es aceptado por el juez, tendríamos, entonces, que la razón suficiente para dar por establecido un hecho no es la prueba sino el consenso que se dio entre los adversarios y el visto bueno del juez.

Además, el artículo 369 de la ley 906 de 2004 contempla las manifestaciones de culpabilidad preacordadas, que permite acuerdos de culpabilidad entre la defensa y la acusación para lo que la Fiscalía deberá indicar al juez los términos de la misma, expresando la pretensión punitiva que tuviere. De igual manera, el artículo 351 de la ley 906 de 2004 faculta al fiscal y el imputado para llegar a un preacuerdo sobre los hechos imputados y sus consecuencias". PUENTES, Orlando Enrique. La doctrina contemporánea sobre la prueba y su aplicación en Colombia. Tésis de Maestría. Bogotá: Universidad Nacional de Colombia -Facultad de Derecho. 2009, p. 24. 
proceso. En el marco de una concepción de este tipo es extremadamente difícil ( $y$, de todas maneras, totalmente inútil) analizar las características y la estructura de la prueba: de hecho, ella es compatible con (más aún, implica) una concepción irracional de la prueba judicial y, en todo caso, no exige que se dé una definición específica de la prueba. (Taruffo, 2006).

En esa medida se sostiene que el fin de la prueba como elaboración de las partes, al menos en un proceso de clara tendencia adscrita al sistema dispositivo y fundamentado en la fijación de los hechos e iniciativa probatoria de las partes, estará orientado a la persuasión del juez con el fin de obtener una resolución judicial favorable a los intereses de alguno de los sujetos de la relación procesal. Con ello, torna en irrelevante la verdad como finalidad del proceso y de la prueba judicial.

En síntesis, si el fin de la prueba y del proceso, no es la verdad, el uso de la ciencia como instrumento para la averiguación de la verdad judicial de los hechos, no tendría importancia en principio. $\mathrm{Si}$ por el contrario, la concepción de la prueba es la que entiende el proceso como un método para el descubrimiento de la verdad posible, en torno a los hechos del juicio, la prueba científica, por ejemplo, correlativamente resulta ser un instrumento epistémico, o sea el medio con el que en el proceso se adquieren informaciones necesarias para la determinación de la verdad de los hechos (Taruffo, 2010) ${ }^{11}$.

11 "El argumento que congrega a quienes niegan que la verdad pueda ser determinada en el proceso, gira usualmente alrededor de la consideración de que el proceso no es un lugar para la investigación científica en el que la verdad pueda ser investigada indefinidamente, y que, por el contrario, está caracterizado por limitaciones de naturaleza diversa: existen, en efecto, normas que excluyen la posibilidad de valerse de determinados tipos de pruebas, normas que prescriben procedimientos particulares para la adquisición de las pruebas, normas que limitan la valoración de la prueba $e$ incluso normas que obligan a poner fin al proceso $y$ establecen - con la cosa juzgada - la inmutabilidad de sus resultados. Todo esto, se dice, haría imposible la búsqueda de la verdad alrededor de los hechos
Como se ha venido expresando, una de las aspiraciones de la epistemología se fundamenta en crear condiciones para que el conocimiento de la realidad sea verdadero. Sin embargo, no existe una única y verdadera teoría del conocimiento que proporcione un concepto de verdad infalible en ninguno de los ámbitos del conocimiento y, por consiguiente, no la hay siquiera para una teoría del proceso y de la prueba judicial. De allí que se hayan estudiado de manera previa las dos principales concepciones acerca de la prueba.

La controversia se establece entre dos tipos de razones. Por una parte, están las razones de la concepción racionalista crítica o cognoscitivista que mencionan un mayor grado de control sobre la motivación judicial en relación con los enunciados sobre los hechos. "Si así no fuese, la valoración, más que libre sería libérrima y esencialmente subjetiva ("íntima" por usar la terminología al uso), con lo cual se abandonaría el cognoscitivismo para entrar en el campo del más puro decisionismo judicial"(Gascón, 2003, p. 50).

Por otra parte, la concepción irracionalista o no-cognoscitivista, indica la existencia ontológica de unos márgenes de relatividad conceptual y retórica en la configuración del criterio de correspondencia de la verdad procesal, toda vez que el proceso no es un laboratorio científico, en donde existe un espacio para la persuasión argumentativa. Este argumento es descrito de la siguiente manera:

La teoría jurídica, cegada en el normativismo, ha olvidado la dimensión de controversia que tiene el proceso; es decir, ha olvidado que el proceso es un espacio de conflicto y no de cooperación; que el proceso -como indica Taruffo- "no

de la causa. Por tanto $-\mathrm{y}$ es la consecuencia que se deriva de allí- es necesario renunciar a laidea de que la verdad de los hechos puede ser establecida en elproceso, a lo sumo, podría hablarse de una verdad $<<$ formal $>>0<$ procesal $>>$, que no tendría nada que ver con la verdad $<<$ verdadera $>>$ que - de nuevo según esta orientación- se podría determinar fuera del proceso". TARUFFO, Michele. Páginas sobre justicia civil. Madrid: Marcial Pons. 2010. p. 413. 
constituye una narración de algo, sino que está formado por una pluralidad de narraciones, cada una de las cuales puede ser verdadera o falsa, (...) que no se recomponen en una sola narración coherente y omnicomprensiva (Gascón, 2003, p. 52).

Es esa la razón a partir de la cual los defensores de la concepción epistemológica cognoscitivista o racional de la prueba reivindican un concepto de verdad que responda a esa fenomenología dialéctica del proceso, que no implique el desconocimiento de esos márgenes constructivos de la prueba, pero tampoco su conformidad con un enfoque esencialista del concepto de verdad ${ }^{12}$.

Como consecuencia, la actividad probatoria dentro del proceso judicial no consiste en establecer la existencia de determinados sucesos óntico-naturales, pero si en construir una serie de narraciones afirmativas o negativas argumentadas como creíbles, acerca de la existencia histórica de un suceso o hecho. Estas narraciones o enunciaciones son distintas del hecho mismo que se quiere probar y usar en el proceso de elaboración de la decisión judicial. "Los enunciados fácticos se conciben como descripciones de hechos que tienen una existencia independiente de esos enunciados; es decir, los enunciados fácticos proporcionan información sobre los hechos, no los constituyen. La pretensión de quien los formula es referirse a una realidad externa"(Gascón, 2010, p. 60).

De tal manera, que el proceso no trata de reproducir objetivamente lo que ha sucedido, sino

12 Pueden consultarse los trabajos más sobresalientes de Michele Taruffo, Marina Gascón Abellán, Jordi Ferrer Beltrán y Jordi Nieva Fenoll acerca de esta concepción de la prueba: "La prueba de los hechos", "Los hechos en el derecho, bases argumentales de la prueba", "Valoración racional de la prueba" y"La valoración de la prueba", respectivamente. Existen otros trabajos notables como "Sobre las fronteras" de Taruffo, "Simplemente la Verdad", "Paginas sobre justicia civil", "La prueba" "Proceso, prueba y estándar" de Gascón Abellán y "Prueba y verdad" y "Valoración racional de la prueba"de Ferrer Beltrán. de elaborar un conjunto de argumentaciones y contrargumentaciones; de aportar datos y permitir la discusión acerca de la existencia y de la forma en que acaecieron los hechos, así como de su calificación o significación jurídica.

\section{EL OBJETO DE PRUEBA: LOS HECHOS O LOS ENUNCIADOS SOBRE LOS HECHOS}

La ciencia se dedica por definición a averiguar y entender hechos. La ciencia jurídica en muchos aspectos utiliza la palabra hecho, y en general la prueba es para verificar hechos relacionados con las alegaciones de las partes. Sin embargo, se observa que no hay una distinción entre hecho y juicio sobre el hecho. Así, el derecho utiliza la palabra hecho a cualquier cosa que sea, o de que se trate, como por ejemplo, todo aquello de lo que sepa o se suponga -con algún fundamento- que pertenece a la realidad (Taruffo, 2010, p. 17).

En las ciencias fácticas un hecho es cualquier cosa que tiene lugar en el espacio-tiempo, se considera en algún respecto como una unidad, además cubre un lapso breve (Bunge, 1983, p. 718). Su significado puede asumir, por lo menos, dos posibilidades semánticas. Una, aquella que define el hecho como "todo aquello que existe en el mundo espacio-temporal"; otra, más específica, que lo concibe como aquello que puede hacer falsas o verdaderas nuestras creencias o proposiciones (González, 2003, p. 18)

En una dimensión epistemológica proyectada hacia lo jurídico se puede hacer una distinción, bajo la cual, en el plano epistémico los hechos no coinciden con los objetos físicos en sí mismos; en cambio, en el ámbito jurídico, particularmente el del proceso judicial, sólo son objeto de prueba los enunciados sobre la existencia de un hecho, más no el hecho en cuanto tal (Corte Suprema de Justicia, 2010, 25 de mayo) $)^{13}$.

13 Veáse Corte Suprema de Justicia. Sala Civil. Sentencia del 25 de mayo de 2010. Expediente No. 23001-3110-002-1998-00467-01. 
Lo que en el supuesto de hecho de un juicio jurídico aparece como "hecho" es el hecho en cuanto enunciado. Lo acaecido tiene que ser mencionado con este fin, y lo mencionado tiene que ser puesto en un cierto orden. El hecho en cuanto enunciado efectúa siempre una selección de la inabarcable profusión, del constante fluir del acontecer fáctico; el que enjuicia encuentra ya esta selección en punto a la posible relevancia jurídica de los hechos particulares (Larenz, 1980, p. 272).

Como consecuencia, la actividad probatoria y la prueba judicial, en su sentido de conocimiento de la existencia o inexistencia de un hecho, son una creencia racional y fundada del juez sobre el hecho.

Jordi Ferrer Beltrán, (2007) expresa como:

[L]os hechos no pueden ser probados en
símismos. Como pone de manifiesto Serra
Domínguez (1962, p. 359), no puede
probarse una mesa, ni un contrato, ni una
obligación. Lo único que puede probarse,
es el enunciado que afirma la existencia
de una mesa en mi despacho, no la mesa
misma. Del mismo modo, puede probarse
el enunciado que afirma (o niega) la firma
de un contrato, etc. En el proceso, por
tanto, deberán probarse los enunciados
sobre los hechosformulados por las partes.

Frente a lo anterior existe una manera clásica de entender la fenomenología de los hechos en el proceso de prueba de los mismos, la cual es derivada de las concepciones epistemológicas empiristas de la realidad, que simplifica el problema de los hechos procesales. Según esta concepción, la de la dogmatica procesal, los "hechos son los hechos"14, y en esa medida la

14 "[L]a congruencia fáctica de las providencias aparece como un requisito enderezado a garantizar que éstas guarden la debida simetría con los supuestos de hecho que apoyan las pretensiones, de manera que la labor del juez no sólo esté orientada por la acción que plantea la parte demandante, sino que también discusión sobre su existencia no es pasible de procesos de interpretación ni de argumentación (Gascón, 2004, p. 75).

En contraste con esa postura, existe otra clasificación alternativa con el discurso iusfilosófico de la prueba que revisa los fundamentos de la tipología tradicional de los hechos, reformulándola según el grado de injerencia de la mente o del sujeto en su conocimiento. Por ello, se habla del dualismo "hechos generales"-"hechos individuales", para distinguir los hechos valorados en el proceso legislativo y en el judicial, respectivamente (González, 2003, p. 18).

Por su parte, en relación con los hechos individuales, se habla de unos (i) "hechos físicos", que pueden ser (a) independientes de la voluntad (los estados de cosas, los sucesos y las acciones involuntarias), o (b) dependientes de la voluntad (acciones propiamente dichas y omisiones, que a su vez pueden ser intencionales o no). (ii) "hechos psicológicos" como (a) los estados mentales (voliciones, creencias o emociones); (b) las acciones mentales; y (c) relaciones de causalidad, que también admiten la adscripción al concepto de hecho (González, 2003, p. 19).

consulte las circunstancias y condiciones concretas que ella adujo para brindarle soporte, constituyéndose así los extremos que trazarán el preciso marco de la tarea judicial, sin que, por lo mismo, la controversia pueda ser desatada por fuera de ellos, pues una actuación semejante desconocería el derecho de defensa, en tanto que el demandado sería llamado a responder por unos hechos diferentes de los que tuvo como referencia para montar su oposición.

Sobre este particular, se tiene dicho que se trata de una "... regla de conducta para el juez, a quien, en consecuencia, se le veda sustentar su decisión en hechos distintos de los consignados por el actor en su demanda. Si el juez rebasa esta regla, o sea, si, prescindiendo del esquema factual trazado en el escrito incoativo del proceso, hace descansar su resolución en una causa petendi, diferente, aún a pretexto de ser ésta la que aparece probada, incurre en incongruencia, la cual, como se sabe, constituye un vicio de actividad, pues aquél habrá desatendido una de las pautas que la ley señala para el proferimiento de la sentencia" (G.J. t. CCXXV, p. 246). Sentencia Sala Civil, Corte Suprema de Justicia, 14 de mayo de 2007. 
Bajo esta misma orientación y como consecuencia de la ambigüedad de la palabra "hecho", es también importante la distinción epistemológica entre "hechos externos", "hechos percibidos" y "hechos interpretados", desde el punto de vista del grado de injerencia de la mente en su conocimiento: los hechos externos son hechos objetivamente ontológicos; los percibidos subjetivamente epistemológicos (intersubjetivos), y los interpretados que también suelen llamarse conceptuales o teóricos -no en bruto - son subjetivos (González, 2000, p. 70).

Estas características alteran la concepción de la teoría procesal clásica frente al objeto de la prueba judicial y llevan a formular la pregunta: ¿̇e prueban "hechos" o "enunciados" -afirmacionessobre los hechos? ${ }^{15}$

Siguiendo la orientación de la prueba bajo el objetivismo crítico o racional, no existe una separación drástica entre hechos objetivos y subjetivos, sino más bien una relación estrecha entre hechos y afirmaciones sobre hechos, que implica una especie de 'núcleo observacional o representativo' para los enunciados o afirmaciones sobre los hechos ${ }^{16}$

15 Entre otros doctrinantes nacionales que sostienen la tesis según la cual el objeto de prueba son los hechos pueden consultarse: DEVIS ECHANDÍA, Hernando. Compendio de derecho procesal, tomo II, $11^{\text {a }}$ edición. Bogotá: ABC. 1998. p. 42; PARRA QUIJANO, Jairo. Manual de derecho probatorio. $17^{\mathrm{a}}$ edición. Bogotá: Profesional. 2009. p. 121; RODRÍGUEZ, Gustavo Humberto. Derecho probatorio colombiano. Quinta edición. Bogotá: Profesional. 1986. Pág. 46; BERTEL OVIEDO, Álvaro. Derecho probatorio partes general y especial. Bogotá: Universidad Santo Tomas - Ibañez. 2009. Pág. 48. En la doctrina foránea explica esta tendencia, así como aquella que señala que el objeto de prueba recae sobre las afirmaciones de hechos: GARCIMARTÍN MONTERO, Regina. El objeto de prueba en el proceso civil. Barcelona: CEDECS. 1997. pp. 45 y s.s.

16 Expresa la C.S. de J. que "La prueba tiene por objeto averiguar o verificar si los hechos que se afirman o enuncian corresponden o no a la realidad. Tales hechos deben ser posibles, verosímiles, pertinentes, relevantes y susceptibles de ser demostrados". Sentencia 29-0905, Expediente No. 22590. "aunque es cierto que el proceso debe operar con afirmaciones sobre los hechos (al igual que ocurre, por ejemplo, con la historia), estas afirmaciones pretenden reflejar o representar la realidad (o hacer creer que la reflejan). "El objetivista crítico debe someter a los hechos a un riguroso análisis para determinar en qué medida son independientes y en qué medida construcciones del observador, así como en qué casos podemos conocerlos con objetividad" (González, 2003, p. 22).

Dicho criterio del núcleo representativo permite efectuar una distinción entre dos tipos de problemas que son esenciales para el análisis de la relación entre la duda y el juicio de prueba: (i) los problemas de percepción, surgidos del hecho hacia el medio probatorio, así como del medio hacia el juez, y que tienen que ver con la duda como producto de la (in)corrección de nuestras percepciones; (ii) los problemas de interpretación de los medios probatorios, que tienen relación con la corrección de de nuestras interpretaciones (González, 2003, p. 19).

En suma, estas distinciones inciden en el concepto de prueba, que pasa de ser un juicio de convicción "íntima" del juez a un procedimiento más complejo, compuesto de un aspecto epistémico y de uno intersubjetivo, mediante el cual el juez valora con criterios de racionalidad crítica, constatación empírica, análisis de los medios de prueba a través de referentes de las ciencias, la veracidad de los enunciados acerca de la existencia y la relevancia normativa de un hecho jurídico individual, centrando esa valoración en el estudio de la validez lógica o en la argumentación que hacen las partes de dichos aspectos de la existencia y de la relevancia normativa del hecho.

Esta dimensión racionalista del concepto de prueba y su concepción de los hechos procesales como enunciados, afirmaciones o aserciones sobre hechos permite destacar de manera importante la relevancia en la clasificación de los hechos la cuestión de la identificación de la fuerza de estos enunciados, que es distinta de su significado, 
desde sus connotaciones constitutiva, normativa y descriptiva. Por ello, a partir de las diferentes clases de fuerza enunciativa es factible postular los enunciados de hecho como constitutivos, normativos y descriptivos (Ferrer, 2002, p. 20).

Un enunciado fáctico posee fuerza constitutiva cuando la determinación judicial de los hechos en el proceso es el resultado de una actividad decisoria, opuesta a una simplemente cognoscitiva; esa fuerza constitutiva imposibilita el análisis del enunciado respecto de su verdad o falsedad y, en esa medida, convierte la decisión en incontrolable racionalmente (Ferrer, 2002. P. 20).

Por su parte, un enunciado fáctico tiene fuerza normativa, cuando entra a formar parte de una decisión cuya conclusión es normativa, es decir, que está reglada por el ordenamiento ${ }^{17}$. En

17 Una aplicación general al proceso en este punto es la explicada por la Corte de Suprema de Justicia al señalar "... que "a la acción civil de carácter privado, en estado de pretensión concreta hecha valer en determinado proceso, la individualizan diferentes elementos que a su vez y obedeciendo a finalidades de notable importancia, son los que permiten identificar la litis objeto de dicho proceso, habida cuenta que según como se presenten tales elementos en la realidad práctica, cada proceso tendrá su propia singularidad,... Sujetos, objeto y causa son, pues, los elementos de toda pretensión por cuyo conducto se obtiene la individualización del contenido litigioso de cada proceso civil en particular, y en cuanto al tercero de esos elementos concierne, debe tenerse presente que lo constituye el conjunto de hechos de relevancia iurídica en que el actor ha fundado la ameritada pretensión,... Dicho en otras palabras, para identificar una pretensión con la exactitud necesaria y evitar de este modo incurrir en los excesos o desviaciones a los que atrás se hizo referencia, no basta atender a lo que se pide sino que respecto a ese 'petitum' que constituye objeto inmediato de la pretensión, el ordenamiento positivo exige que se le ponga en relación con la causa de pedir invocada, expresión esta que según acaba de verse, comprende tanto la concreta situación de hecho aducida como las consecuencias jurídicas que a esa misma situación le asigna el demandante, de lo que se sigue, entonces, que el elemento identificador en estudio lo componen dos factores enlazados entre sí en estrecha conjunción que de acuerdo con la perspectiva que de esta última aporta la demanda, tampoco puede serle indiferente a los sentenciadores quienes, además de exhaustivos en el pronunciamiento decisorio frente a todos los temas tanto los elementos del razonamiento judicial, incluyendo los de la premisa fáctica, se encuentran institucionalmente configurados por las normas jurídicas generales, en él tampoco hay lugar a predicar valor de verdad o falsedad. No puede

materia de debate, deben ser respetuosos de dicha conjunción y considerarla en su integridad".

"Esos dos factores, componentes inseparables de la 'causa petendi', determinan la razón de ser o el 'título' de la pretensión, título en cuya configuración concurren unas razones de hecho y otras de derecho, entendiendo que las primeras vienen dadas por el relato histórico de todas las circunstancias fácticas de las que se pretende deducir aquello que se pide de la jurisdicción, mientras que las segundas son afirmaciones concretas de carácter iurídico que referidas a esos antecedentes de hecho, le permiten al demandante autoatribuirse el derecho subjetivo en que apova su solicitud de tutela a las autoridades iudiciales, afirmaciones estas que, desde luego, no hay lugar a confundir en modo alguno con los motivos abstractos de orden legal que se aduzcan para sustentar la demanda incoada... En efecto, al llevar a cabo la tarea, de suyo exigente en grado sumo, de identificar el objeto del proceso en un supuesto dado, obligado es no perder de vista que en lo atinente a la trascendencia jurídica que de dicho objeto pueda predicarse, a su turno juegan papel dos ingredientes cuyo alcance, en el plano que aquí importa destacar, ninguna semejanza tiene: En primer lugar, ha de tomarse muy en cuenta la significación jurídica particularizada de la situación de hecho descrita en la demanda, entendida como el agregado de consecuencias relevantes que el ordenamiento liga a dicha situación y hace posible que la tutela solicitada del poder jurisdiccional del Estado sea esa y no otra distinta, las más de las veces resultante esta última de la simple imaginación de sus órganos; y en segundo lugar, la mención de las reglas de derecho objetivo que en opinión del demandante son aplicables y por ende justifican su pretensión, factor este último ajeno a la delimitación de la 'causa petendi' y por ello no vinculante en la sentencia que va a proferirse, lo que no acontece con el primero puesto que si bien es cierto que a los jueces les ha sido reservada la misión de efectuar la correcta calificación jurídica de los hechos litigados que resulten probados,..., aquellos funcionarios no cuentan con autoridad ninguna para, en correría ilimitada y arbitraria, llegar hasta desestimar las susodichas declaraciones, seleccionando de oficio acciones y vías legales no utilizadas por las personas legitimadas para hacerlo, luego salta a la vista la especial importancia que tiene la escogencia de la acción y la manera de enderezarla,..." (G.J. CCLVIII, págs. 109,110; Se subraya y resalta). Sentencia C. S. de J., SC-084 de 2007. 
dejarse de lado que en ese razonamiento judicial en que está inmersa la conclusión normativa, median premisas fácticas que no pierden esa condición por la circunstancia de su institucionalización jurídico-general (Ferrer, 2002) ${ }^{18}$.

Un enunciado sobre hechos tiene fuerza descriptiva en tanto expresa una proposición descriptiva acerca de la ocurrencia de un determinado hecho en un contexto de realidad foráneo al proceso, razón por la cual es pasible de ser valorado en términos de su verdad o falsedad. De tal forma que justificada la validez de una teoría epistemológica objetivista crítica que vincula la prueba procesal con la verdad, cobra valor esta fuerza descriptiva de los enunciados declarativos de hechos probados -fácticos- como la de mayor corrección epistemológica, por razones de coherencia lógica, y también axiológica (Ferrer, 2002).

Estas clasificaciones permiten establecer otra distinción que resulta más relevante, bien respecto de las clasificaciones antecedentes como de la postura respecto de las relaciones entre verdad y prueba, a efectos de consolidar una teoría de prueba provista de mejores elementos epistemológicos. Es la distinción entre enunciados fácticos o que se refieren a hechos verdaderos y enunciados fácticos probados: Prueba y argumentación.

De tal modo, expresar que un enunciado fáctico es verdadero o que refleja la verdad material $u$ objetiva, significa que los hechos que describe han existido o existen en un mundo independiente; o sea, que es correcta, en el sentido de que se corresponde con la realidad, la descripción de hechos que formula. Por lo cual:

[D]ecir que un enunciado fáctico está probado (o que constituye la verdad procesal o formal) significa que su verdad ha sido comprobada; o sea, que el enunciado ha sido confirmado por las pruebas disponibles. (...) dicha distinción tiene la virtualidad de poner de relieve

18 FERRER BELTRAN, Jordi. Ob. Cit., pp. 20 y s.s. las inevitables limitaciones que el procedimiento probatorio padece a la hora de averiguar lo que efectivamente ha sucedido: aunque sólo la declaración de hechos probados o verdad procesal resulta jurídicamente relevante, no es infalible, $y$ desde luego puede ser distinta (de menor o mayor calidad) a la obtenida a través de otros procedimientos que no tengan las trabas y limitaciones procesales"(Gascón, 2003, p. 46).

\section{CONCLUSIONES}

En síntesis, podemos señalar a modo de conlusiones de este corto trabajo las siguientes:

Se resalta y explica la importancia de la espistemología en el acercamiento teórico de los hechos y su conocimiento dentro del ámbito del proceso judicial.

El concepto de verdad alcanzable dentro del proceso en relación con el de prueba en las tendencias contemporáneas de la prueba se realiza en términos de probabilidad.

El juicio de hecho en el proceso exige diferenciar una faceta epistemológica y otra normativa, las cuales se relacionan en un momento particular del proceso: al establecer los hechos relevantes del caso -hechos a probar-y al valorar si ellos se encuentran corroborados - hechos probados-.

Se ha mostrado la relevancia de los hechos como premisa del clásico silogismo judicial.

Por último, se clasifican los hechos en diversas categorías tomando como punto de partida de que en realidad no se habla de "hechos puros" sino de ennunciados o proposiciones acerca de ellos. Todo ello tiene la utilidad de servir para afrontar mejor la prueba de un hecho concreto, una vez deducida su clasificación. Aunque su utilidad, se traduce principalmente en la ordenación de ideas. 


\section{BIBLIOGRAFÍA}

BERTEL OVIEDO, Álvaro. (2009) Derecho probatorio partes general y especial. Bogotá: Universidad Santo Tomas - Ibañez.

BUNGE, Mario. (1983). La investigación científica. Barcelona: Ariel. 1983.

\section{CORTE SUPREMA DE JUSTICIA. SALA CIVIL.} CORTE CONSTITUCIONAL.

DEVIS ECHANDÍA, Hernando. (1998) Compendio de derecho procesal, tomo II, $11^{\text {a }}$ edición. Bogotá: ABC.

FERRAJOLI, Luigi. (1997). Derecho y razón. Madrid: Trotta. 1997.

FERRER BELTRÁN, Jordi. (2007). La valoración racional de la prueba. Marcial Pons.

(2002). Prueba y verdad. Marcial Pons.

GARCIMARTíN MONTERO, Regina. (1997). El objeto de prueba en el proceso civil. Barcelona: CEDECS.

GASCÓN ABELLÁN, Marina. (2010). Los hechos en el derecho, bases argumentales de la prueba. Madrid: Marcial Pons, $3^{a}$ edición.

(2005). La argumentación en el derecho. Segunda edición. Lima: Palestra.

(2004). Los hechos en el derecho. Madrid: Marcial Pons, $1^{\mathrm{a}}$ edición.

(2003). La prueba judicial: valoración racional y motivación. Universidad de Castilla-la Mancha: Discusiones.

(2003). Concepciones de la prueba. Madrid: Discusiones, No. 04. 2003.
GONZALEZ LAGIER, Daniel. (2003). Hechos y argumentos (Racionalidad epistemológica y prueba de los hechos en el proceso penal) I. Jueces para la democracia No.46.

(2000). Los hechos bajo sospecha. Analisi e diritto, Universitá degli Studi di Génova, Génova.

LARENZ, Karl. (1980). Metodología de la ciencia del derecho. Segunda edición definitiva. Barcelona: Ariel.

MONTERO AROCA, Juan. (2007). La prueba en el proceso civil. Navarra: Thomson - Civitas.

(2006). coordinador, et al. Proceso civil e ideología. Valencia: Tiran lo Blanch.

NIEVA FENOLL, Jordi. (2010). La valoración de la prueba. Marcial Pons.

PARRA QUIJANO, Jairo. (2009). Manual de derecho probatorio. $17^{\mathrm{a}}$ edición. Bogotá: Profesional.

PEÑA AYAZO, Jairo Iván. (2008). Prueba judicial, análisis y valoración. Módulo de capacitación para Jueces. Bogotá: Consejo Superior de la Judicatura - Escuela Judicial "Rodrigo lara Bonilla"- Universidad Nacional de Colombia.

RODRÍGUEZ, Gustavo Humberto. (1986). Derecho probatorio colombiano. Quinta edición. Bogotá: Profesional.

TARUFFO, Michele. (2002). La prueba de los hechos. Madrid: Trotta.

(2010). Páginas sobre justicia civil. Madrid: Marcial Pons.

(2010). La prueba. Madrid: Marcial Pons.

(2010). Simplemente la verdad. Marcial Pons. 